\title{
Epitaxial Growth of Room-Temperature Ferrimagnetic Semiconductor Thin Films Based on $\mathrm{Fe}_{3} \mathrm{O}_{4}-\mathrm{Fe}_{2} \mathrm{TiO}_{4}$ Solid Solution
}

\author{
Hideaki Murase*1, Koji Fujita*2, Shunsuke Murai and Katsuhisa Tanaka \\ Department of Material Chemistry, Graduate School of Engineering, Kyoto University, Kyoto 615-8510, Japan
}

Spinel-type $0.4 \mathrm{Fe}_{3} \mathrm{O}_{4} \cdot 0.6 \mathrm{Fe}_{2} \mathrm{TiO}_{4}$ (molar ratio) solid solution thin films have been deposited on $c$-sapphire substrates by a pulsed laser deposition technique. A single phase of (111)-oriented solid solution can be obtained by adjusting the oxygen partial pressure and substrate temperature. The epitaxial solid solution thin film exhibits ferrimagnetism with Curie temperature above room temperature and is a semiconductor with $n$-type conduction carriers. Anomalous Hall effect is observed at room temperature for the solid solution thin films, implying the presence of spin-polarized charge carriers. [doi:10.2320/matertrans.MC200804]

(Received November 5, 2008; Accepted January 19, 2009; Published March 18, 2009)

Keywords: ferrimagnetic semiconductor, thin film, $\mathrm{Fe}_{3} \mathrm{O}_{4}-\mathrm{Fe}_{2} \mathrm{TiO}_{4}$ solid solution, pulsed laser deposition

\section{Introduction}

Recently, materials having high spin polarization of conducting charge carriers have attracted considerable attention due to their potential application in spintronics, a technology simultaneously utilizing both the charge and spin degrees of freedom of carriers. ${ }^{1)}$ In particular, magnetite $\left(\mathrm{Fe}_{3} \mathrm{O}_{4}\right)$ is a promising candidate for functional spintronics devices that operate efficiently at room temperature, because it has high Curie temperature $\left(T_{\mathrm{c}} \sim 860 \mathrm{~K}\right)$ and is theoretically predicted to be a half-metal with $100 \%$ spin polarization.,3) $\mathrm{Fe}_{3} \mathrm{O}_{4}$ has inverse spinel-type structure $(F d 3 m)$ with a face-centered cubic (fcc) oxide ion sublattice, in which half of $\mathrm{Fe}^{3+}$ ions occupy the tetrahedral (A) sites, and the other half of $\mathrm{Fe}^{3+}$ ions and all $\mathrm{Fe}^{2+}$ ions are located at the octahedral (B) sites. The superexchange interaction between $\mathrm{Fe}^{3+}$ ions in the $\mathrm{A}$ and $\mathrm{B}$ sites plays the most important role in magnetic structure and transition of $\mathrm{Fe}_{3} \mathrm{O}_{4}$, while the electrical conduction stems from the electron hopping between $\mathrm{Fe}^{3+}$ and $\mathrm{Fe}^{2+}$ ions in the $\mathrm{B}$ sites. The device implementation such as magnetic tunnel junctions using $\mathrm{Fe}_{3} \mathrm{O}_{4}$ as ferromagnetic electrodes has been demonstrated, ${ }^{4)}$ although the tunnel magnetoresistance effect near room temperature is much lower than would be expected for the bulk. Very recently, spinel-type $\mathrm{Fe}_{3} \mathrm{O}_{4}-\mathrm{Fe}_{2} \mathrm{MO}_{4}$ solid solutions $\left(\mathrm{M}=\mathrm{Mn}^{2+}, \mathrm{Zn}^{2+}\right)$, where $\mathrm{M}^{2+}$ ions preferentially occupy the A-sites in the spinel structure, have been exploited for application in semiconductor spintronics. ${ }^{5-7)}$

Here we have focused on the spinel-type solid solutions of $\mathrm{Fe}_{3} \mathrm{O}_{4}$ and $\mathrm{Fe}_{2} \mathrm{TiO}_{4}$ (ülvospinel). According to previous studies, bulk specimens of $(1-x) \mathrm{Fe}_{3} \mathrm{O}_{4}-x \mathrm{Fe}_{2} \mathrm{TiO}_{4}$ (molar ratio) forms a complete series of solid solutions in a range of $0<x<1 .^{8-10)}$ The uniqueness of this solid solution system lies in the fact that the conduction type can be easily controlled by changing the chemical composition $x$; $n$-type conduction is obtained for the compositions of $x \leq 0.6$, while the compositions of $x \geq 0.7$ show $p$-type conduction. ${ }^{10)} \mathrm{In}$ addition, the solid solution system has superiority that $T_{\mathrm{c}}$ of some compounds $(x<0.8)$ is above room temperature

\footnotetext{
${ }^{* 1}$ Graduate Student, Kyoto University

${ }^{* 2}$ Corresponding author, E-mail: fujita@dipole7.kuic.kyoto-u.ac.jp
}

regardless of the conduction type. ${ }^{8)}$ In spite of such intriguing properties, there exist no reports on preparation of the $\mathrm{Fe}_{3} \mathrm{O}_{4}-\mathrm{Fe}_{2} \mathrm{TiO}_{4}$ solid solution in the form of thin films, to the best of our knowledge. In this study, we have prepared $0.4 \mathrm{Fe}_{3} \mathrm{O}_{4} \cdot 0.6 \mathrm{Fe}_{2} \mathrm{TiO}_{4}$ solid solution thin films on sapphire substrates using a pulsed laser deposition (PLD) technique and examined their structural, electrical, and magnetic properties.

\section{Experimental Procedures}

Thin films with $0.4 \mathrm{Fe}_{3} \mathrm{O}_{4} \cdot 0.6 \mathrm{Fe}_{2} \mathrm{TiO}_{4}$ composition (molar ratio) were grown on the (0001) surface ( $c$-plane) of sapphire $\left(\alpha-\mathrm{Al}_{2} \mathrm{O}_{3}\right.$ single crystal) substrates by a PLD technique. The $c$-sapphire substrates were annealed at $1000^{\circ} \mathrm{C}$ in air for $3 \mathrm{~h}$ to obtain atomically flat surface. The target for PLD was prepared from reagent-grade $\alpha-\mathrm{Fe}_{2} \mathrm{O}_{3}$ and $\mathrm{TiO}_{2}$ by the solid-state reaction; first, the mixture of $\alpha-\mathrm{Fe}_{2} \mathrm{O}_{3}$ and $\mathrm{TiO}_{2}$ powders was sintered at $1200^{\circ} \mathrm{C}$ for $12 \mathrm{~h}$ in air, and then heattreated in $\mathrm{CO}(40 \%)-\mathrm{CO}_{2}$ (balance) atmosphere at $800^{\circ} \mathrm{C}$ for $24 \mathrm{~h}$ in order to convert some of $\mathrm{Fe}^{3+}$ to $\mathrm{Fe}^{2+}$ ions. The deposition chamber had a base pressure of $\sim 10^{-6} \mathrm{~Pa}$, and the target to substrate distance was $3.5 \mathrm{~cm}$. A focused $\mathrm{KrF}$ excimer laser with a wavelength of $248 \mathrm{~nm}$ and a pulse duration of $20 \mathrm{~ns}$ was used as a light source for PLD. The repetition frequency was $2 \mathrm{~Hz}$, the laser fluence was about $1.3 \mathrm{~J} / \mathrm{cm}^{2}$, and the deposition rate was $0.67 \mathrm{~nm} / \mathrm{min}$. To obtain optimal deposition conditions, oxygen partial pressure, $P_{\mathrm{O}_{2}}$, and substrate temperature, $T_{\mathrm{s}}$, were varied from $1.0 \times 10^{-5}$ to $1.0 \times 10^{-3} \mathrm{~Pa}$ and from 500 to $700^{\circ} \mathrm{C}$, respectively.

The thickness and chemical composition of thin film were determined by Rutherford backscattering spectroscopy (RBS) using $2.0 \mathrm{MeV} \mathrm{He}^{2+}$. The analysis of RBS spectra with SIMNRA simulation program revealed that the film thickness was $40 \mathrm{~nm}$ and that the ratio of $\mathrm{Fe}$ to $\mathrm{Ti}$ was typically $0.799: 0.201$, consistent with the value expected from the chemical composition of $0.4 \mathrm{Fe}_{3} \mathrm{O}_{4} \cdot 0.6 \mathrm{Fe}_{2} \mathrm{TiO}_{4}$. Xray diffraction (XRD) analysis with $\mathrm{Cu} K \alpha$ radiation (Rigaku, SLX2500K and ATX-G) was performed in $2 \theta / \omega$ scans (outof-plane), $2 \theta_{\chi} / \phi$ scans (in-plane), $\omega$ scans (rocking curve), and $\phi$-scans. Magnetization as a function of external 

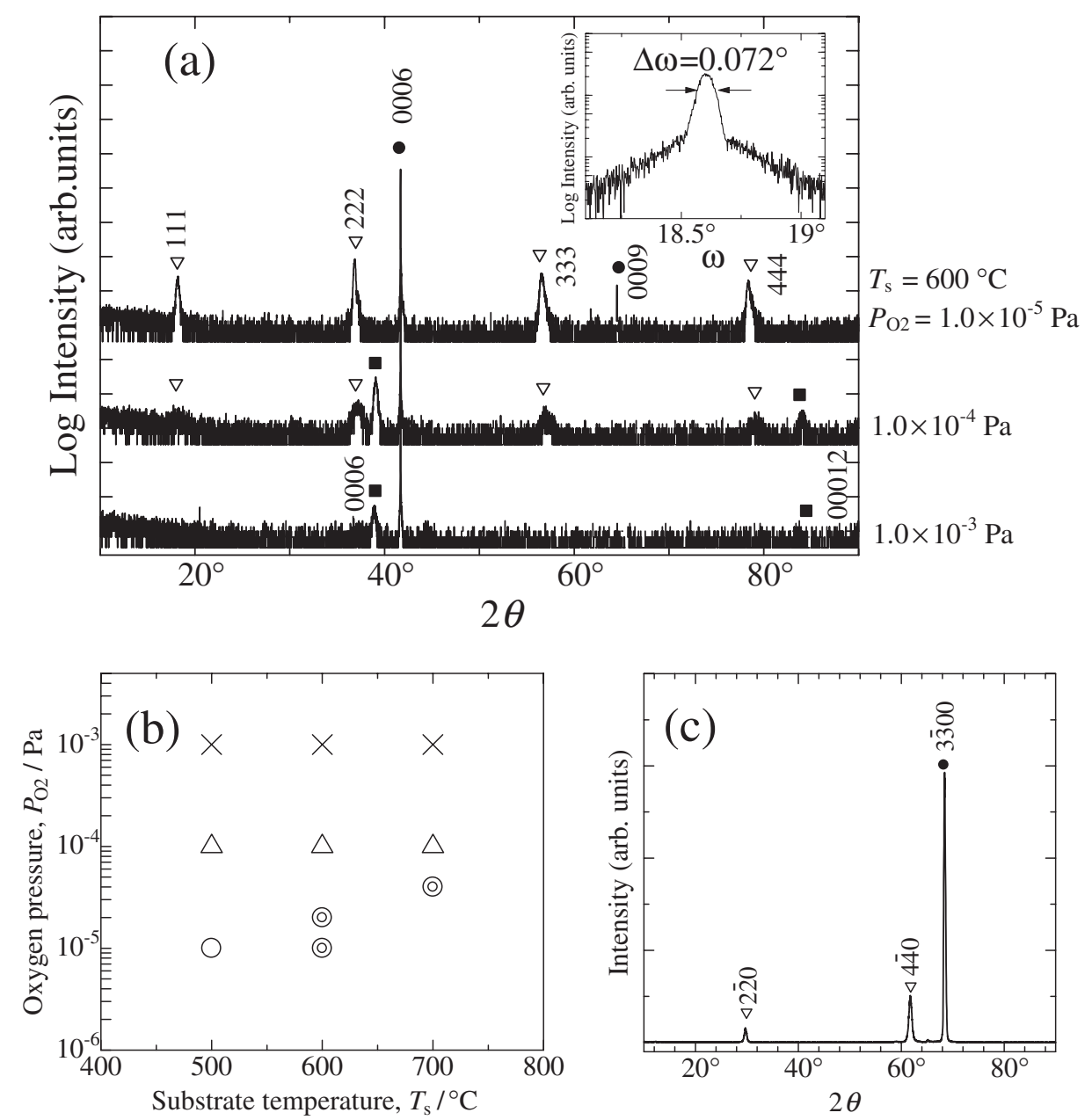

Fig. 1 (a) XRD $2 \theta / \omega$ scans of thin films grown under varied oxygen pressure at $600^{\circ} \mathrm{C}$. Inset shows the rocking curve of 222 reflection in the $\mathrm{Fe}_{3} \mathrm{O}_{4}-\mathrm{Fe}_{2} \mathrm{TiO}_{4}$ solid solution thin films grown under $1.0 \times 10^{-5} \mathrm{~Pa}$ and at $600^{\circ} \mathrm{C}$. $\nabla: \mathrm{Fe}_{3} \mathrm{O}_{4}-\mathrm{Fe}_{2} \mathrm{TiO}_{4}$ solid solution, $\mathbf{\square}$ : $\mathrm{FeTiO}_{3}-\mathrm{Fe}_{2} \mathrm{O}_{3}$ solid solution, $\boldsymbol{O}$ : $\alpha-\mathrm{Al}_{2} \mathrm{O}_{3}$ (substrate). (b) Variation in the crystalline phase with the deposition conditions $\left(T_{\mathrm{s}}\right.$ and $\left.P_{\mathrm{O}_{2}}\right) \odot$ : $\mathrm{Fe}_{3} \mathrm{O}_{4}-\mathrm{Fe}_{2} \mathrm{TiO}_{4}$ solid solution with high crystallinity, $\bigcirc$ : $\mathrm{Fe}_{3} \mathrm{O}_{4}-\mathrm{Fe}_{2} \mathrm{TiO}_{4}$ solid solution with low crystallinity, $\triangle$ : Coexistence of $\mathrm{Fe}_{3} \mathrm{O}_{4}-\mathrm{Fe}_{2} \mathrm{TiO}_{4}$ and $\mathrm{FeTiO}_{3}-\mathrm{Fe}_{2} \mathrm{O}_{3}$ solid solutions, $\times$ : FeTiO $\mathrm{F}_{3}-\mathrm{Fe}_{2} \mathrm{O}_{3}$ solid solution. (c) XRD $2 \theta_{x} / \phi$ scan of the thin film grown under $1.0 \times 10^{-5} \mathrm{~Pa}$ and at $600^{\circ} \mathrm{C}$. $\nabla: \mathrm{Fe}_{3} \mathrm{O}_{4}-\mathrm{Fe}_{2} \mathrm{TiO}_{4}$ solid solution, $: \alpha-\mathrm{Al}_{2} \mathrm{O}_{3}($ substrate).

magnetic field and temperature was measured by a superconducting quantum interference device (SQUID) magnetometer (Quantum design, MPMS). Temperature dependence of electric resistivity was explored by the van der Pauw method (Resitest8300, TOYO). Hall effect measurements were performed at room temperature for photolithographically patterned Hall bars using a physical property measurement system (Quantum design, PPMS). To cancel the effect of magnetic field on the longitudinal resistivity, the magnetic field was swept to a positive region and then to a negative region so that only the transverse resistivity, i.e., Hall resistivity, could be obtained by half the difference between the signals measured at the positive and negative fields. In order to determine the major conduction type in thin films, Seebeck coefficient was determined by using two R-type thermocouples attached to both ends of the film, while utilizing a heater to induce a temperature difference of $2 \mathrm{~K}$ at room temperature.

\section{Results and Discussion}

\subsection{Structural analysis}

Figure 1(a) shows the XRD $2 \theta / \omega$ scan profiles of the thin films grown at $T_{\mathrm{s}}=600^{\circ} \mathrm{C}$ and under varied $P_{\mathrm{O}_{2}}$. The thin film grown under $P_{\mathrm{O}_{2}}=1.0 \times 10^{-5} \mathrm{~Pa}$ can be identified as a single phase of (111)-oriented spinel-type $\mathrm{Fe}_{3} \mathrm{O}_{4}$ $\mathrm{Fe}_{2} \mathrm{TiO}_{4}$ solid solution without any impurity phases. When $P_{\mathrm{O}_{2}}$ is increased to $1.0 \times 10^{-4} \mathrm{~Pa}$, another crystalline phase ascribed to the solid solution of ilmenite $\left(\mathrm{FeTiO}_{3}\right)$ and hematite $\left(\mathrm{Fe}_{2} \mathrm{O}_{3}\right)$ appears in addition to the $\mathrm{Fe}_{3} \mathrm{O}_{4}-\mathrm{Fe}_{2} \mathrm{TiO}_{4}$ solid solution. At $P_{\mathrm{O}_{2}}=1.0 \times 10^{-3} \mathrm{~Pa}$, the diffraction peaks due to the $\mathrm{Fe}_{3} \mathrm{O}_{4}-\mathrm{Fe}_{2} \mathrm{TiO}_{4}$ solid solution disappear, and only diffraction peaks due to the $\mathrm{FeTiO}_{3}-\mathrm{Fe}_{2} \mathrm{O}_{3}$ solid solution are detected. Figure 1(b) summarizes the change in crystalline phase with the deposition conditions $\left(T_{\mathrm{s}}\right.$ and $\left.P_{\mathrm{O}_{2}}\right)$. Both lower $P_{\mathrm{O}_{2}}$ and higher $T_{\mathrm{s}}$, which promote the formation of $\mathrm{Fe}^{2+}$ ions, are effective in stabilizing the spinel phase of $\mathrm{Fe}_{3} \mathrm{O}_{4}-\mathrm{Fe}_{2} \mathrm{TiO}_{4}$ solid solution without the precipitation of $\mathrm{FeTiO}_{3}-\mathrm{Fe}_{2} \mathrm{O}_{3}$ solid solution. In the inset of Fig. 1(a) is displayed the rocking curve for the 222 reflection of the $\mathrm{Fe}_{3} \mathrm{O}_{4}-\mathrm{Fe}_{2} \mathrm{TiO}_{4}$ solid solution thin film grown under $P_{\mathrm{O}_{2}}=1.0 \times 10^{-5} \mathrm{~Pa}$ and at $T_{\mathrm{s}}=600^{\circ} \mathrm{C}$. A single peak is observed with a full width at half maximum (FWHM, $\Delta \omega$ ) of $0.072^{\circ}$. This value is typical for most of the films with single-phase $\mathrm{Fe}_{3} \mathrm{O}_{4}$ $\mathrm{Fe}_{2} \mathrm{TiO}_{4}$ solid solution, except for the sample prepared under $P_{\mathrm{O}_{2}}=1.0 \times 10^{-5} \mathrm{~Pa}$ and at $T_{\mathrm{s}}=500^{\circ} \mathrm{C}$. For the thin film 


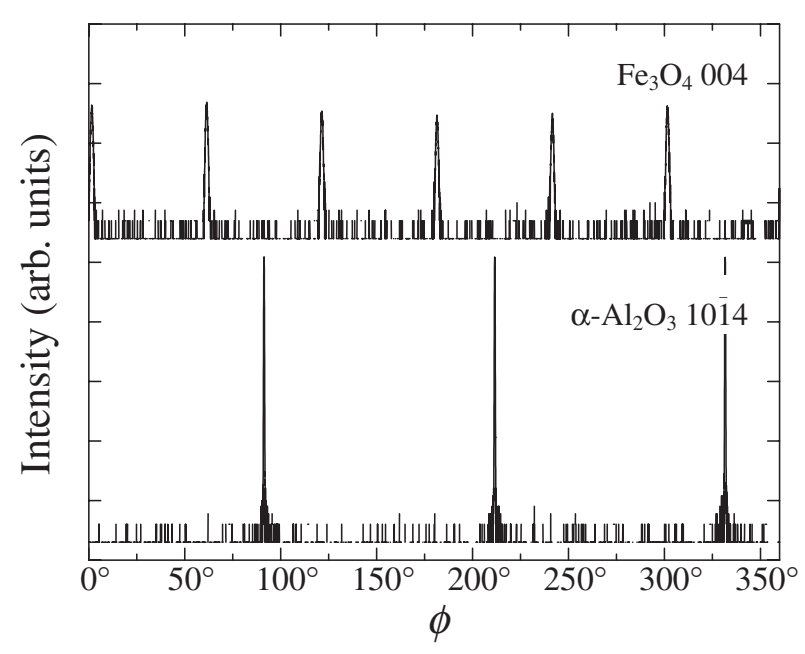

Fig. $2 \phi$-scan of 004 reflection in the solid solution thin film grown under $1.0 \times 10^{-5} \mathrm{~Pa}$ and at $600^{\circ} \mathrm{C}$. For comparison, $\phi$-scan of $10 \overline{1} 4$ reflection in sapphire substrate is also shown.

grown under $P_{\mathrm{O}_{2}}=1.0 \times 10^{-5} \mathrm{~Pa}$ at $T_{\mathrm{s}}=600^{\circ} \mathrm{C}$, the out-ofplane lattice parameter was calculated to be $0.8483 \mathrm{~nm}$ from the peak position of the 222 reflection shown in Fig. 1(a). In the $2 \theta_{\chi} / \phi$ scan measured for the same film (Fig. 1(c)), the in-plane lattice parameter was estimated to be $0.8496 \mathrm{~nm}$ by using the $2 \overline{2} 0$ reflection. These lattice parameters of the film are very close to that of bulk specimen $(0.8489 \mathrm{~nm})$. The small deviation between out-of-plane and in-plane lattice parameters is presumably due to a substrate-induced strain.

To examine the in-plane alignment for the thin films, XRD $\phi$-scan was carried out using the 004 reflection $\left(2 \theta=42.7^{\circ}\right.$, $\psi=54.7^{\circ}$ ) of the solid solution. A typical result is depicted in Fig. 2 for the thin film composed of the single phase grown under $P_{\mathrm{O}_{2}}=1.0 \times 10^{-5} \mathrm{~Pa}$ and at $T_{\mathrm{s}}=600^{\circ} \mathrm{C}$. Also shown in the figure is the $\phi$-scan in the $10 \overline{1} 4$ reflection $(2 \theta=$ $\left.35.141^{\circ}, \psi=38.236^{\circ}\right)$ of the $c$-sapphire substrate. The (0001) surface of substrate has threefold symmetry, so that only three peaks are observed in the $\phi$-scan from $0^{\circ}$ to $360^{\circ}$. If the resultant film is a perfect single crystal, only three peaks should be detected at every $120^{\circ}$ in the $\phi$-scan due to the threefold symmetry relative to the [111] direction. For the present film, however, six peaks corresponding to the sixfold symmetry are observed, indicating that the thin film has two crystallographic domains turned by $60^{\circ}$ or $180^{\circ}$ with each other on the surface of $c$-sapphire substrate. The formation of twinned in-plane alignment is ascribable to the large lattice mismatch $(10.7 \%)$ between the solid solution thin film and the $c$-sapphire substrate. ${ }^{11)}$ Based on the results shown in Figs. 1 and 2, the epitaxial relation can be evaluated to be; $\mathrm{Fe}_{3} \mathrm{O}_{4}-\mathrm{Fe}_{2} \mathrm{TiO}_{4}$ solid solution (111) $\| \alpha-\mathrm{Al}_{2} \mathrm{O}_{3}(0001)$ and $\mathrm{Fe}_{3} \mathrm{O}_{4}-\mathrm{Fe}_{2} \mathrm{TiO}_{4}$ solid solution [1 $\left.\overline{1} 0\right] \| \alpha-\mathrm{Al}_{2} \mathrm{O}_{3}$ [1 1100$]$ and $[1 \overline{100]}$.

\subsection{Physical properties}

Figure 3 shows the temperature dependence of magnetization, $M$, for the solid solution thin film grown under $P_{\mathrm{O}_{2}}=1.0 \times 10^{-5} \mathrm{~Pa}$ and at $T_{\mathrm{s}}=600^{\circ} \mathrm{C}$. The measurements were performed under field-cooling condition with an external magnetic field, $H$, of $0.85 \mathrm{~T}$ applied parallel to the

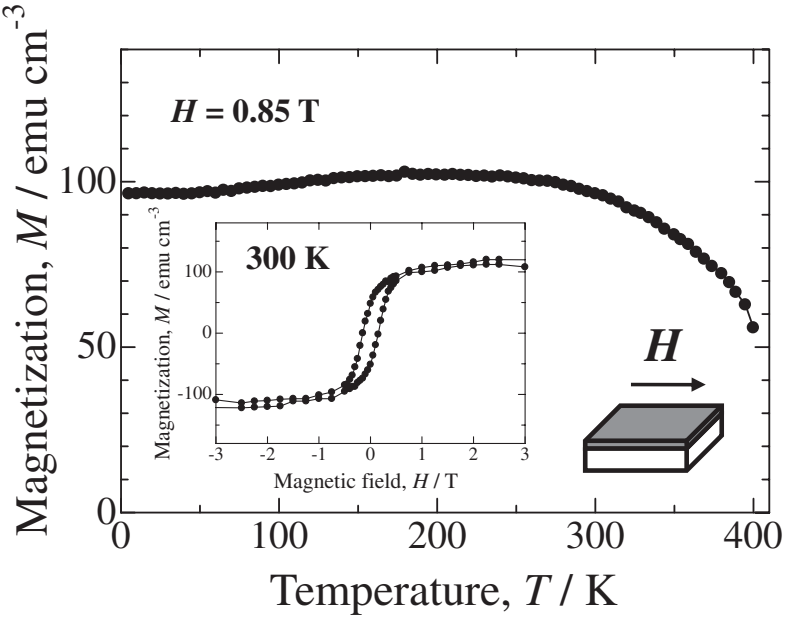

Fig. 3 Temperature dependence of magnetization, $M$, for the solid solution thin film measured under field-cooling condition at $H=0.85 \mathrm{~T}$. Inset shows room-temperature $M-H$ curve.

thin film surface. One can see that $M$ exhibits a plateau at 5 to $300 \mathrm{~K}$ and begins to decrease above $300 \mathrm{~K}$, but does not reach zero even at $400 \mathrm{~K}$. This observation indicates that the solid solution thin film shows ferrimagnetism with $T_{\mathrm{c}}$ above $400 \mathrm{~K}$. The inset of Fig. 3 displays the in-plane $M-H$ curve at roomtemperature for the solid solution thin film. The $M-H$ curve exhibits an obvious hysteresis loop with saturation magnetization of $0.81 \mu_{\mathrm{B}} / \mathrm{mol}$ at room temperature $\left(1.0 \mu_{\mathrm{B}} / \mathrm{mol}\right.$ at $5 \mathrm{~K}$, not shown here). The saturation magnetization of the present thin film is smaller compared with the value of single crystal $\left(1.5 \mu_{\mathrm{B}} / \mathrm{mol}\right.$ at $\left.77 \mathrm{~K}\right) .{ }^{9)}$ This is generally explained by the presence of antiphase boundaries (APBs) where antiferromagnetic interactions are dominant in the films. ${ }^{12,13)}$ APBs are structural defects formed during the growth process, and are observed when growing $\mathrm{Fe}_{3} \mathrm{O}_{4}$ epitaxial thin films. ${ }^{14-16)}$

In Fig. 4(a) is depicted the temperature dependence of electric resistivity, $\rho_{x x}$, for the solid solution thin film grown under $P_{\mathrm{O}_{2}}=1.0 \times 10^{-5} \mathrm{~Pa}$ and at $T_{\mathrm{s}}=600^{\circ} \mathrm{C}$. A typical semiconducting behavior is observed between 77 and $325 \mathrm{~K}$. The value of $\rho_{x x}$ at $300 \mathrm{~K}$ is $0.87 \Omega \mathrm{cm}$, which is almost consistent with those of single crystals. ${ }^{10)}$ For the purpose of evaluating the conduction mechanism, two types of analyses were performed as shown Figs. 4(b) and (c). In a high temperature range between 100 and $325 \mathrm{~K}$, the relation between logarithmic $\rho_{x x}$ and reciprocal temperature $\left(T^{-1}\right)$ exhibits Arrhenius-type behavior as shown in Fig. 4(b):

$$
\rho_{x x}=\rho_{0} \exp \left(E_{\mathrm{g}} / k_{\mathrm{B}} T\right),
$$

where $\rho_{0}, E_{\mathrm{g}}$, and $k_{\mathrm{B}}$ are the preexponential term, the activation energy, and the Boltzmann constant, respectively. The $E_{\mathrm{g}}$ is estimated to be $0.055 \mathrm{eV}$ from the slope of the line. On the other hand, the $\log \rho_{x x}-T^{-1}$ plot in a low temperature range obviously shows deviation from the linear relation. In a temperature range from 77 to $160 \mathrm{~K}$, a linear relationship is observed between $\log \rho$ and $T^{-1 / 4}$ as shown in Fig. 4(c), following the Mott formula $\left(T^{-1 / 4}\right.$ law): ${ }^{17)}$

$$
\rho_{x x}=\rho_{0} \exp \left(T_{0} / T\right)^{1 / 4},
$$





Fig. 4 (a) Temperature dependence of electric resistivity, $\rho_{x x}$, for solid solution thin film. Dependence of $\log \rho_{x x}$ on (b) $T^{-1}$ and (c) $T^{-1 / 4}$.

where $T_{0}$ is the Mott temperature. This conducting behavior is derived from the variable range hopping (VRH). From these plots, the conduction behavior is found to change from the VRH to the simple thermal-activated hopping at a critical temperature $(141 \mathrm{~K})$, suggesting that the charge carriers in the solid solution thin film localize at low temperatures. The Seebeck coefficient of the thin film was evaluated to be $-6.0 \mu \mathrm{V} / \mathrm{K}$, which is coincident with the value of bulk sample as reported previously. ${ }^{10}$ ) The negative Seebeck coefficient indicates that the charge carrier is an electron (n-type).

Figure 5 shows the magnetic field dependence of the Hall resistivity, $\rho_{\mathrm{H}}$, measured at room temperature for the thin film grown under $P_{\mathrm{O}_{2}}=1.0 \times 10^{-5} \mathrm{~Pa}$ and at $T_{\mathrm{s}}=600^{\circ} \mathrm{C}$. The magnetic field was applied perpendicular to the thin film surface. We found that $\rho_{\mathrm{H}}$ is negative at room temperature

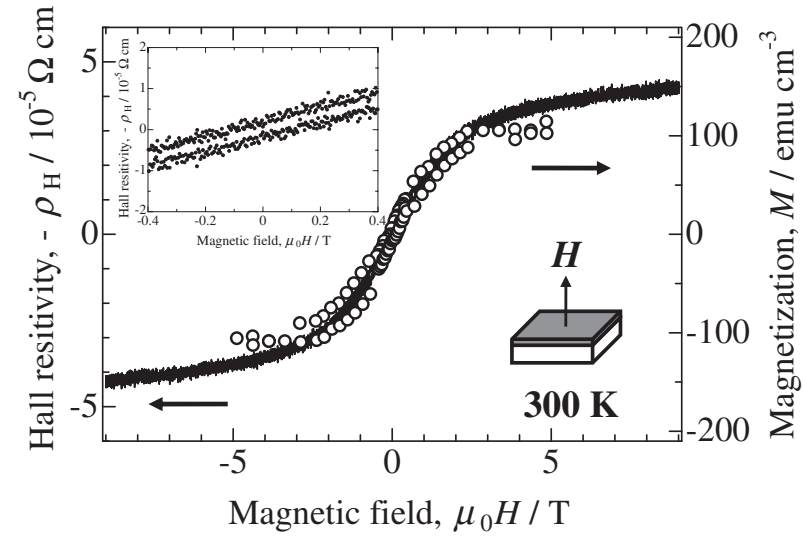

Fig. 5 Magnetic field dependence of $-\rho_{\mathrm{H}}$ and magnetization (open circles) for solid solution thin film. The inset shows a magnified view of magnetic field dependence of $-\rho_{\mathrm{H}}$.

(this is why $-\rho_{\mathrm{H}}$ is plotted in the ordinate of Fig. 5). The plot of out-of-plane $M-H$ curve is also illustrated in Fig. 5. The hysteresis behavior of out-of-plane $M-H$ curve is smaller than that of in-plane shown in Fig. 3, suggesting the presence of easy axis of magnetization in the in-plane direction. In ferromagnetic materials, the Hall resistivity is generally expressed as ${ }^{18)}$

$$
\rho_{\mathrm{H}}=R_{\mathrm{O}} \mu_{0} H+R_{\mathrm{A}} \mu_{0} M,
$$

where $R_{\mathrm{O}}$ is the ordinary Hall coefficient, $R_{A}$ is the anomalous Hall coefficient, and $\mu_{0}$ is the vacuum permeability. The first term of eq. (3), proportional to $H$, describe the ordinary Hall effect (OHE), and the second term, in general much larger than the first one, denotes the anomalous Hall effect (AHE), which is proportional to $M$ of the material. The OHE arises from the Lorentz forces acting on charge carriers. On the other hand, although the origin of AHE has been a controversial issue for decades, ${ }^{19-22)}$ it has been considered that AHE in a ferromagnetic material provides a strong evidence of intrinsic ferromagnetism caused by spin-polarized charge carriers that mediate ferromagnetic exchange interaction between localized spins of magnetic ions distant from each other. ${ }^{22)}$ As shown in Fig. 5, $\rho_{\mathrm{H}}$ exhibits a behavior similar to that of out-of-plane $M-H$ curve, especially in the low magnetic fields. The result suggests that $0.4 \mathrm{Fe}_{3} \mathrm{O}_{4} \cdot 0.6 \mathrm{Fe}_{2} \mathrm{TiO}_{4}$ solid solution thin film has spin-polarized charge carriers at room temperature. From the slope of the line at high magnetic fields caused by $\mathrm{OHE}$, we can obtain $R_{\mathrm{O}}=-1.17 \times 10^{-2} \mathrm{~cm}^{3} / \mathrm{C}$ at room temperature, indicating $n$-type conduction, consistent with the Seebeck effect measurement. The carrier density, $n$, determined by using the relation $R_{\mathrm{O}}=1 /$ en is $5.35 \times$ $10^{20} \mathrm{~cm}^{-3}$. The Hall mobility derived from $R_{\mathrm{O}}$ and conductivity $\left(1 / \rho_{\mathrm{xx}}\right)$ is $0.01 \mathrm{~cm}^{2} \mathrm{~V}^{-1} \mathrm{~s}^{-1}$. Substituting the saturation magnetization $\left(102 \mathrm{emu} \mathrm{cm}^{-3}\right)$ into the second term of eq. (3) yields $R_{\mathrm{A}}=-2.48 \mathrm{~cm}^{3} / \mathrm{C}$ at room temperature. The negative value of $R_{\mathrm{A}}$ has been commonly observed in $\mathrm{Fe}_{3} \mathrm{O}_{4}\left(R_{A}=-0.25 \mathrm{~cm}^{3} / \mathrm{C}\right)$ and related compounds. ${ }^{23)}$ In order to clarify the mechanism of AHE in more detail, a relation between $\rho_{\mathrm{H}}$ and $\rho_{\mathrm{xx}}$ should be investigated in a systematic fashion as reported in literatures. $^{24-26)}$ 


\section{Conclusion}

We have fabricated 40 -nm-thick $0.4 \mathrm{Fe}_{3} \mathrm{O}_{4} \cdot 0.6 \mathrm{Fe}_{2} \mathrm{TiO}_{4}$ solid solution thin films with spinel-type structure on $c$ sapphire substrates by using a PLD technique, and examined their structural, electrical, and magnetic properties. The solid solution thin films are epitaxially grown on the sapphire substrate, although they have a preferential in-plane orientation due to the large lattice mismatch between the thin film and the substrate. The crystallographic relationship is $\mathrm{Fe}_{3} \mathrm{O}_{4}$ $\mathrm{Fe}_{2} \mathrm{TiO}_{4}$ solid solution (111) $\| \alpha-\mathrm{Al}_{2} \mathrm{O}_{3}(0001)$ and $\mathrm{Fe}_{3} \mathrm{O}_{4}$ $\mathrm{Fe}_{2} \mathrm{TiO}_{4}$ solid solution [1 $\left.\overline{1} 0\right] \| \alpha-\mathrm{Al}_{2} \mathrm{O}_{3}[\overline{1} 100]$ and [1 $\left.\overline{1} 00\right]$. The solid solution thin film is ferrimagnetic with $T_{\mathrm{c}}$ higher than $400^{\circ} \mathrm{C}$, and shows $n$-type conduction. The conduction behavior changes from the simple thermal-activated hopping to the VRH at a critical temperature $(141 \mathrm{~K})$ due to the localization of electrons at low temperatures. The presence of spin-polarized charge carriers is suggested by the Hall effect measurement at room temperature. These results imply that the solid solution thin film can be a promising candidate for semiconductor spintronics devices.

\section{Acknowledgement}

The authors thank Prof. M. Suzuki of Kyoto University for Hall effect measurements and Dr. H. Tsuchida and Prof. A. Ito of Kyoto University for RBS measurements. This study was financially supported by the Grant-in-Aid for Scientific Research (B) (No. 19360298) and Scientific Research on Priority Areas (No. 20047008) from the Ministry of Education, Culture, Sports, Science and Technology (MEXT), Japan. A part of this work was also conducted in KyotoAdvanced Nanotechnology Network, supported by "Nanotechnology Network" of MEXT, Japan.

\section{REFERENCES}

1) J. M. D. Coey and C. L. Chien: MRS Bull. 28 (2003) 720.

2) A. Yanase and K. Siratori: J. Phys. Soc. Jpn. 53 (1984) 312.
3) Z. Zhang and S. Satpathy: Phys. Rev. B 44 (1991) 13319.

4) X. W. Li, A. Gupta, G. Xiao, W. Qian and V. P. Dravid: Appl. Phys. Lett. 73 (1998) 3282.

5) M. Ishikawa, H. Tanaka and T. Kawai: Appl. Phys. Lett. 86 (2005) 222504.

6) J. Takaobushi, H. Tanaka, T. Kawai, S. Ueda, J.-J. Kim, M. Kobata, E. Ikenaga, M. Yabashi, K. Kobayashi, Y. Nishino, D. Miwa, K. Tamasaku and T. Ishikawa: Appl. Phys. Lett. 89 (2006) 242507.

7) I. Saitoh, J. Takaobushi, H. Tanaka and T. Kawai: Solid State Comm. 147 (2008) 397.

8) E. SchmidBauer and P. W. Readman: J. Magn. Magn. Mater. 27 (1982) 114.

9) Z. Kakol, J. Sabol and J. M. Honig: Phys. Rev. B 43 (1991) 649.

10) V. A. M. Brabers: Physica B 205 (1994) 143.

11) I. Yamaguchi, T. Terayama, T. Manabe, T. Tsuchiya, M. Sohma, T. Kumagai and S. Mizuta: J. Solid State Chem. 163 (2002) 239.

12) D. T. Margulies, F. T. Parker, F. E. Spada, R. S. Goldman, J. Li, R. Sinclair and A. E. Berkowitz: Phys. Rev. B 53 (1996) 9175.

13) D. T. Margulies, F. T. Parker, M. L. Rudee, F. E. Spada, J. N. Chapman, P. R. Aitchison and A. E. Berkowitz: Phys. Rev. Lett. 79 (1997) 5162.

14) F. C. Voogt, T. T. M. Palstra, L. Niesen, O. C. Rogojanu, M. A. James and T. Hibma: Phys. Rev. B 57 (1998) R8107.

15) W. Eerenstein, T. T. M. Palstra, T. Hibma and S. Celotto: Phys. Rev. B 66 (2002) 201101(R).

16) A. V. Ramos, J.-B. Moussy, M.-J. Guittet, M. Gautier-Soyer, M. Viret, C. Gatel, P. Bayle-Guillemaud and E. Snoeck: J. Appl. Phys. 100 (2006) 103902.

17) N. F. Mott: J. Non-Crystal. Solids 1 (1968) 1.

18) C. L. Chien and C. R. Westgate: The Hall Effect and its Applications, (Plenum, New York, 1980).

19) R. Karplus and J. M. Luttinger: Phys. Rev. 95 (1954) 1154.

20) J. Smit: Physica 24 (1958) 39.

21) L. Berger: Phys. Rev. B 2 (1970) 4559.

22) H. Toyosaki, T. Fukumura, Y. Yamada, K. Nakajima, T. Chikyow, T. Hasegawa, H. Koinuma and M. Kawasaki: Nature Mater. 3 (2004) 221.

23) D. Reisinger, P. Majewski, M. Opel, L. Alff and R. Gross: Appl. Phys. Lett. 85 (2004) 4980.

24) T. Miyasato, N. Abe, T. Fujii, A. Asamitsu, S. Onoda, Y. Onose, N. Nagaosa and Y. Tokura: Phys. Rev. lett. 99 (2007) 086602.

25) D. Venkateshvaran, W. Kaiser, A. Boger, M. Althammer, M. S. R. Rao, S. T. B. Goennenwein, M. Opel and R. Gross: Phys. Rev. B 78 (2008) 092405.

26) A. Fernandez-Pacheco, J. M. De Teresa, J. Orna, L. Morellon, P. A. Algarabel, J. A. Pardo and M. R. Ibarra: Phys. Rev. B 77 (2008) $100403(\mathrm{R})$. 